\title{
I mproving the knowledge exchange landscape in the Cape Flats, a developing community in South Africa
}

\author{
M.Parker * \\ Cape Peninsula University of Technology, Cape Town, South Africa \\ parkerm@cput.ac.za
}

\section{G. Wills}

Learning Societies Lab, University of Southampton, Southampton, United Kingdom gbw@soton.ecs.ac.uk

\begin{abstract}
South Africa has a national shortage of Information Communication and Technology (ICT) personnel. Great strides are being made to improve the level of ICT literacy among the school population. However, it will take some time before the current school population has the necessary background training needed to use ICT in a corporate setting and fill this gap. Web 2.0 services have created a virtual world that brings people closer through the formation of networks. Web 2.0 services tend to be single function, easy-to-use tools. This research explored the use of Web 2.0 services to lower the barrier to take-up of ICT, by people living in a socially and economically deprived area, and affected by gangsterism and drugs. This article reports on an investigation into the use of Web 2.0 technologies to enhance the information flow within the community to assist preventing the growth and spread of gangsterism and the use of drugs among South African communities, especially those in the Cape Flats. Ex-gang members and ex-drug addicts were interviewed, none of whom finished high school or had previous experience of using ICT. The findings showed that, through the use of Web 2.0 technologies, interviewees learnt to use, exchange and disseminate information.
\end{abstract}

Key words: Web 2.0, knowledge exchange, information, developing communities, Information Communication and Technology (ICT)

Received 25 May 2009

\section{Contents}

1. I ntroduction

2. Social networking technology

2.1 Social networking: keeping in touch with friends

2.2 Social networking: getting the knowledge disseminated

3. Case study

4. Findings

5. Discussion

6. Conclusions and recommendations

7. References

\section{I ntroduction}

There are great strides being made to improve the computer literacy of communities within South Africa. For example, in 2001 the Western Cape Education Department instigated the Khanya project for deployment of computers in schools in the Western Cape. To date, 813 of 1570 public schools have been provided with technology facilities, typically computer laboratories, consisting of between 25 and 40 computers each (LAN networked and Internet linked); in total, 32011 PCs have been deployed in these schools. The Provincial Government of the Western Cape has invested more than 
R250 million ( $\$ 32 \mathrm{~m}$ ) in this initiative. Part of the development plan allows the local community to access these facilities for the enhancement of adult learning and, in particular, computer literacy. In turn, local communities contribute to the establishment of technology facilities in schools in conjunction with the state (see khanya.co.za).

However, the reality is that for most of the school day the equipment is locked away. In part this is because ICT is not imbedded into the curriculum, and in part because the teachers are not trained to use the technology. Likewise, for good security reasons, the buildings are locked while learners are not at the school. The first issue will gradually be solved and more of the school learners will be ICT literate. In the meantime, there are many citizens and possible workforce, in the Republic of South Africa, not receiving ICT training.

At the same time, the African market for mobile telecommunications has been the fastest-growing market of all regions, expanding at twice the rate of the global market. Investment in the ICT sector in Africa has been primarily in the mobile industry and has resulted in increased coverage of these mobile communications networks. It is estimated that almost $100 \%$ of the population in South Africa live within range of a mobile communication network. There are now at least five times more mobile than fixed-telephone subscribers in South Africa (World Bank 2007). In the Western Cape, more than $60 \%$ of households have access to mobile phones (see capegateway.gov.za).

Although access to technology seems to be available (java-enabled mobile phones, computers, etc.) in many communities, it is not being appropriated by the community due to the relatively high cost of ownership and running costs, lack of relevant skills and barriers to the use of technologies. This research therefore investigated the use of Web 2.0 technologies as a means of lowering the barriers to unskilled people being able to exchange and disseminate information, thereby improving the general ICT literacy for these people.

In this article, the authors report on a case study that investigated the use of Web 2.0 technologies in order to lower the barrier of learning to use ICT and how the mobile phone can play a major part in appropriating these skills. The people in the case study did not complete (or even start) their high school education. The article presents a literature review of the technology, a description of the case study and the methodology used. The findings of the case study are followed by a discussion on these findings.

\section{Social networking technology}

From a worldwide perspective, Web 2.0 is a formed collection of newly usable Web applications. These applications have been constructed for user-added content in an ever-changing data and technology environment.

Tim O'Reilly describes the difference between Web 1.0 and Web 2.0 stating,

'You can visualize Web 2.0 as a set of principles and practices that tie together a veritable solar system of sites that demonstrate some or all of those principles, at a varying distance from that core' (O'Reilly 2005).

Web 2.0 focuses on being a medium to share views and information by self-publishing, using fully established tools. The Web as a whole has established itself as a solid platform for Web 2.0 applications, hence the rapid usage and growth. The other effect is that there are many free or lowcost applications available that are being utilised by almost everyone who has access to the Internet (Peek 2005).

Social networking services essentially entail the use of Websites that allow people the opportunity to share, network and create content about themselves and other interests. The Internet communities form what are called 'social networks' where people can keep in touch with each other, meet new people and develop virtual friendships. Examples of social network technologies include chat rooms, community sites and bulletin boards. Individuals can interact with each other by chatting, messaging, file-sharing, voice chatting and blogging. The uniqueness of social networking is that it permits individuals to construct social networks of their own and interact with each other using new methods and technologies that continue to develop and evolve (Goodings, Locke and Brown 2007; Kay 2007). 
People on such sites are interested in communicating with people who are already part of their social network or community. According to Kay (2007), from the early evolution of social networks, blogging has been the technology that showed the most rapid growth. Blogs were originally used as online personal diaries, but today they can be used in several different forms, from informed personals giving opinions on the latest technologies to projects charting their progress in the development life cycle. Two sites that have been a great success in their implementation as part of social networks are Facebook and MySpace (Kay 2007). Facebook as a means of communicating with friends and blogs as a means to disseminate information are described below.

\section{top}

\subsection{Social networking: keeping in touch with friends}

Facebook is a social networking site with more than 190 million users and is expanding at a fast rate (Lorica 2009). Facebook has revolutionised the way communication takes place within communities, from educational institutions to business organisations. Facebook was established in 2004 as a means by which students could communicate with their friends, share information and media content. Facebook is continuing to reach out to people as a means of daily communication and interaction within societies.

Facebook has now expanded to cover both the public and the corporate world. Many businesses are using Facebook for marketing and advertising. The advertising potential is unlimited because business organisations can advertise and access online communities all over the world and at any time of the day. Advertising by businesses is the primary source of income for social networking Websites (Buice, Heath, Simmons, Smith and Syeda 2007). According to Frauenheim (2007), social networking tools such as Facebook could benefit organisations as a channel for unofficial but vital information, in order to improve communication and collaboration among employees.

Facebook has been used to form discussion groups among students, lecturers and librarians and found to be more effective in the dissemination of information to new students, as students paid more attention to information posted in Facebook than that posted via their email (Frauenheim 2007). These students also showed more openness and willingness to share information about each other, individual projects and group projects. Mathews (2006) reports that students from Georgia Institute of Technology also responded quicker to Facebook postings than campus emails.

Green (2005) mentiones that Facebook can facilitate healthy real-life relationships among people. Furthermore, Ellison, Steinfield and Lampe (2007) report that Facebook usage was found to improve the psychological well-being and thus uplifted self-esteem among individuals experiencing low selfesteem and low life satisfaction. This emanates from encouraging comments posted by the online communities on personal profiles and pictures. Buice et al. (2007) also mention that social networking tools such as Facebook could help people stay in touch with one another much easier, owing to the greater conveniences afforded by the Internet technology. Comparing a number of offline and on-line friends, Ellison (2007) reports that the majority of people on Facebook use it primarily to restore, enhance, maintain and solidify existing offline relationships.

\section{top}

\subsection{Social networking: getting the knowledge disseminated}

Blogs, also known as 'Weblogs', are one of the tools that have become one of the more used and popular Web 2.0 applications. Blogs also form a technological component of social networking that lets users interact, share and create content as they please (Dearstyne 2005).

The 'blogosphere' is common terminology associated with blogs and blogging (Holahan 2007). It simply expresses the virtual world that consists of bloggers tracking and posting information on blogs (Stanfield 2007). The structure of blogs, consisting of the original post and comments following each other ordered by latest post, makes it easy for visitors to blogs to find a particular topic and once they start blogging, it makes them feel as though they are part of a continuous dialogue. These are valid types of topics and information that can be present on blogs. Some blogs are dedicated to presenting specific types of information (Dearstyne 2005).

Blogs act as pull broadcast facilities, to which people can respond or not respond if they wish to. Generally, it is a non-intrusive technology, since the user has to go and read a posting on a blog (Nardi, Schiano, Gumbrecht and Swartz 2004). In essence, blogging is about providing valuable or 
interesting information to a community. It is not about displaying as much information as possible, but relevant information. This will result in more people seeking a specific blog (Stanfield 2007).

Blogging is not a formal method of communication and as such can lead to the use of 'sloppy writing', the use of abbreviations for instance 'message' typed as 'msg', and incorrect grammar (Doring and Gundolf 2006). In some cases where blogs are open to the public, bloggers that initially put up posts for the purpose of getting opinions or reactions from other people might receive hurtful feedback in the form of comments. This contributes to the argument whether the freedom of speech associated with blogging is actually good or not. The ability to post anything certainly has two sides (Davies 2005; Vaughan 2006). Anyone with non-substantive evidence, or even false information, can publish through the medium of a blog (Roth 2004). Generally blogs are public, which illustrates a lack of security in terms of the information that bloggers put on the blogs, as anyone has access to that information at any time (Al-Fadhli 2008). However, blogs can be restricted to an intranet.

\section{Case study}

A case study approach was used to examine the effects of Web 2.0 technologies on individuals and the group as a whole. By using Web 2.0 technologies, the authors aimed to lower the barrier to learning ICT skills and generally improve the computer literacy of the individuals.

Blogging and social networking proved to be the Web 2.0 technologies of choice among the interviewees in that all of the individuals were using it. Other technologies were being used but not as often as blogging and social networking tools.

The Cape Flats is an area of Cape Town that was established through the 'forced removals' during the apartheid era. There is racial, economic and spatial segregation between the coloured communities and African townships (Standing 2003). With the standard of living being low and high unemployment rates, communities in the Cape Flats have been plagued with violence and substance abuse issues (Parker, Wills and Wills 2008).

The population recruited for this case study were from a non-governmental organisation (NGO), namely I mpact Direct Ministries (IDM). The people interviewed were known as the Impact Team, a community empowerment group for ex-drug addicts and ex-gang members, established by IDM in 2001.

The Impact Team came from the region called the Cape Flats in the city of Cape Town, Republic of South Africa. The individuals were in the 'reconstructed' phase, as in the past they had been the casualties of a harmful environment that consisted of drugs and gangs. The fact that they resided in communities with tension gave more reason in understanding why these individuals had been vulnerable to what they had experienced and continued to fight against it.

A group of 12 members of the Impact Team were interviewed. Two of the 12 completed high school, while the least formally educated individuals left after primary school. The ages of the interviewees ranged from 17 to 32 years. In South Africa, youth is defined to up to the age of 35 (see capegateway.gov.za). All the interviewees could therefore be defined as 'youth' in the South African context. The period of drug addiction ranged between four and 13 years, four of the respondents were involved in drug dealing, seven were involved in gang-related crime, four in petty crime, and all of them had a substance abuse problem.

None of them had a computer at home or received any computer training prior to the start of this project. In the group, nine of the interviewees had mobile phones of which eight were J ava enabled and could access the Internet. All of the respondents had used a mobile phone for calling, sms (text messaging), data transfer and multimedia (photos/videos). Only two of them had never heard about the Internet, whereas three of the 12 had exposure to browsing the World Wide Web. None of the interviewees had an email address or any presence on social networks. All of the participants lived on the Cape Flats and only three of them had employment. The rest were volunteering their time to the local NGO to support other members of the community who were impacted by the problem of substance abuse.

A qualitative case study approach was used as this methodology allows for the study of meanings and experiences rather than with a quantitative approach that deals essentially with numbers. Hence, this approach is part of an inductive research that moves from individual observation to 
discovering general patterns. Inductive research entails generating theories and hypotheses on the basis of studying specific cases. For this reason, it was decided to use a case study as research method. Ehrmann's triad model (1998) was used as an overview to understand the case study (see Figure 1).

Figure 1 Triad model adapted from Ehrmann (1998)

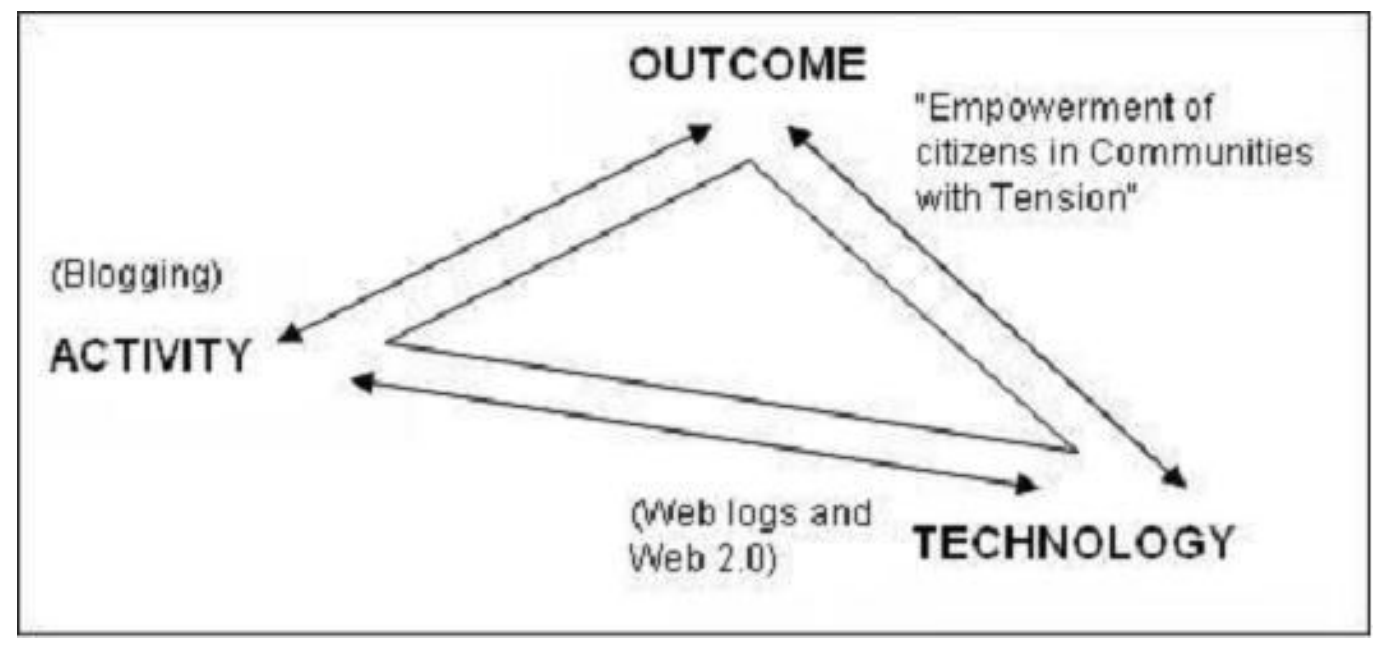

Welman, Kruger and Mitchell (2005) point out that unstructured interviews offer more information than other methods of collecting data and that unstructured interviews are usually used in explorative research because of their qualitative nature. With regard to Erhmann's triad model (Figure 1) and its relation to this study, the technology aspect illustrated in the model was the use of Web logs. The activities were related in the form of self-expression such as the individual's feelings, stories and testimonies through the motion of blogging. At the end, an outcome would be generated, focusing on empowering the individuals.

The qualitative approach adopted for data collection was the use of semi-structured in-depth interviews. In this type of interview, sensitive and emotional questions can be asked of the individuals, resulting in a greater wealth of data. The interviews are conducted on a one-to-one basis or in random groups of three or four, providing data from different perspectives which allow for discussion of opinions and experiences (Welman et al. 2005).

The interview for the blogging consisted of questions that enquired:

- What the individuals thought about blogging as a technology

- What they accomplished and how they benefited from blogging

- General questions such as how often they visited the blog and how often they put up new posts or comments.

For the interviews regarding the social networking tool, Facebook, questions of the 'what' and 'why' types were prepared and used in order to understand experiences of the Impact Team members before, during and after their involvement with gang- and drug-related activities. The interviews were carried out on a one-to-one and face to faceapproach.

top

\section{Findings}

Only five of the 12 interviewees would blog three or more times a week, whereas 11 of the 12 interviewees would be on Facebook almost daily, updating their status, messaging or posting to their walls.

During the interviews, it was realised that ex-gang members and ex-drug addicts used Facebook to strengthen their communication among themselves and the community at large. Eleven reported using the 'text message' and the 'chat' facilities of Facebook. However, five mentioned writing on their friends' walls. The status update on profile, which allows a Facebook user to mention his current situation/status, received much attention among this group. Impact team members used this status update feature as a flag to determine the present social condition of their fellow members. 
They would then communicate among each other in order to uplift individuals with low self-esteem.

Before using Facebook for social purposes, some of the Impact Group members mentioned they had been using MXIT, a cell phone-enabled social networking feature. When they heard about Facebook for the first time, they equated it to MXIT. As such, they prejudged that Facebook had no meaning because little was achieved via MXIT. However, after attending Internet and social media classes (Web 2.0 training), they engaged in exploring Facebook. The immediate feedback from friends, coupled with encouragement messages, struck most of them. It is this spirit of encouragement and hope among themselves and the community that kept their self-esteem high. One interviewee mentioned that 'Facebook was capable of bringing hope to hopelessness'.

Ten interviewees talked about participating in the drug abuse and gangsterism advice service. They mentioned the fact that, having suffered the consequences of gangsterism and drug abuse, they were willing to reach out to the youth and share their experiences. They found that using Facebook could be a useful tool in reaching out to young people who might become caught up in the world of drugs and gangs. Nevertheless, they mentioned the fact that the high rate of Internet and computer illiteracy could be an impeding factor for success. They suggested that if Web 2.0 training could be available for community members, Facebook would go a long way in reaching out to communities. Without the Web 2.0 training, they believed community members would fear to touch a computer because of not knowing how to use it. To reach out to such people, basic computer training is essential, as in the Web 2.0 training. This stresses the fact that dissemination of information about the Internet, and computer literacy, could play a big role in bringing the communities in touch with online communities or social networks.

One interviewee told a success story about a young woman who had marital problems owing to drug abuse and had resorted to self-injury in order to feel better. Without this painful habit of cutting her body to bleed, this woman became so depressed that she considered committing suicide. Some members of the Impact Team noticed her status on Facebook and began to communicate with her by sharing messages of hope. Thus she received social encouragement using Facebook as a medium. This intervention led to the woman going for counselling.

Most importantly, the Impact Team reported that Facebook played a big role in keeping the group united and updated with how they were dealing with issues. They also used it as a means of supporting one another. These people believed that unity was essential if they were to succeed in reaching out to their communities. To strengthen the communication bond among group members and to ensure that no member was left behind, the Impact Team used Facebook as a medium of communication. This not only strengthened the social interactions among themselves, but it kept all members motivated and uplifted while discouraging members from reverting back to drugs and gangsterism.

For the use of blogs, one focus group interview was conducted with four individuals selected randomly from the 12 , and the other eight were interviewed on a one-to-one basis. Their first post gave some background about themselves. Subsequent posts consisted of information such as selfexpression concerning the individuals' feelings, the activities that were going on or what the individual was doing every day. Table 1 summarises what they liked and disliked about the blogging experience.

Table 1 Likes and dislikes about blogging

\begin{tabular}{|l|l|}
\hline \multicolumn{1}{|c|}{ Likes } & \multicolumn{1}{|c|}{ Dislikes } \\
\hline Allowed individuals to write about anything & $\begin{array}{l}\text { Individuals had to use computer technology } \\
\text { and for some of them this meant they had to } \\
\text { step out of their comfort zones }\end{array}$ \\
$\begin{array}{l}\text { Allowed them to help others by providing } \\
\text { encouragement or guidance through the use of } \\
\text { scriptures from the Bible (e.g. help someone } \\
\text { who is down as determined by their status on } \\
\text { Facebook: 'I'm having a bad day') }\end{array}$ & $\begin{array}{l}\text { The fact that blogging is reliant on the use of } \\
\text { a computer and their centre was not that } \\
\text { well-equipped }\end{array}$ \\
$\begin{array}{l}\text { Meeting new people (all over the world, } \\
\text { different cultures, diversity) }\end{array}$ & $\begin{array}{l}\text { Might be bad if young people read some of } \\
\text { the experiences and try to do the same }\end{array}$ \\
$\begin{array}{l}\text { Comments, form of feedback (can learn and } \\
\text { grow from constructive criticism) }\end{array}$ &
\end{tabular}


'Relief and happiness' were the answers of individuals when they were asked how they felt about blogging. The blogging platform gave them an outlet to express themselves and share information with others that they deemed to be useful. One individual felt nervous at the thought of putting posts up that could be read by potentially millions of people around the world. Individuals felt that they benefited from blogging as they could express and pour out their feelings without being judged by anyone or feeling guilty about anything. They felt that the blog provided allocated 'space' for them, which acted as a form of representation of each individual. One individual said 'J ust having something positive next to your name on the blog brought some satisfaction for me'. The majority felt that receiving comments from other bloggers, whether these were good or bad, did help them. Eleven individuals obtained basic computer skills, such as operating the computer (on, off, navigation, use of the mouse, keyboard) and information management (using file sharing tools such as YouTube and Flickr).

The group was also asked a series of questions, of which the results are summarised in Table 2.

- What was the objective of their blogging?

- Why would they encourage others to blog?

- What did they think of the technology?

Table 2 Summary of the response to the questions

\begin{tabular}{|l|l|l|}
\hline Objective & Why encourage others? & $\begin{array}{l}\text { I nterpretation of the } \\
\text { technology }\end{array}$ \\
\hline $\begin{array}{l}\text { To present hope in any } \\
\text { situation (their stories give } \\
\text { other young people, parents } \\
\text { and family members hope } \\
\text { that they can overcome the } \\
\text { problems they are } \\
\text { experiencing due to drugs and } \\
\text { gang activity) }\end{array}$ & $\begin{array}{l}\text { They can express their } \\
\text { feelings }\end{array}$ & $\begin{array}{l}\text { Facility that allows you to } \\
\text { update what you are currently } \\
\text { doing }\end{array}$ \\
\hline $\begin{array}{l}\text { To inform others what the } \\
\text { individuals are doing at the } \\
\text { Impact Centre in terms of } \\
\text { how they are impacting } \\
\text { people's lives (as up to date } \\
\text { as they possibly could) }\end{array}$ & $\begin{array}{l}\text { People can learn about things } \\
\text { they don't already know about } \\
\text { themselves and to encourage } \\
\text { others by reading the posts }\end{array}$ & An international diary \\
\hline $\begin{array}{l}\text { Expressing themselves } \\
\text { To help people (by hearing } \\
\text { someone else's view, it might } \\
\text { aid them whatever problem } \\
\text { they may be battling with) }\end{array}$ & $\begin{array}{l}\text { You can learn more about } \\
\text { people (different cultures, } \\
\text { religions and beliefs) }\end{array}$ & $\begin{array}{l}\text { An outlet for messages (hope) } \\
\text { anonymously } \\
\text { you are feeling or what is on }\end{array}$ \\
\hline & $\begin{array}{l}\text { You can become more } \\
\text { computer literate }\end{array}$ & $\begin{array}{l}\text { Providing information that } \\
\text { might assist those who are } \\
\text { reading the posts }\end{array}$ \\
\hline
\end{tabular}

During the first week, the individuals visited the blog every day (sometimes twice a day) and made one posting each time. After three months, they visited the blog once a week and some once every two weeks owing to problems with availability and capability of the technology, for example bandwidth at the IDM centre. This situation arose as more and more of the team were using the available resources. The individuals attempted to post something every week or whenever they had access to a computer. At the end of the research period, there were over 250 posts on the blog (see www.thereconstructed.blogspot.com).

Most of the individuals knew the basics of a computer (switching on and playing games), but some had never even used one before. These individuals found the general use of the computer a challenge in itself as it was something new for them. The rest were confident and found the opportunity to learn more exciting, especially other Internet and mobile-based technologies. 
The usage of the blogging technology allowed the individuals to explore various aspects of the Internet. Common technologies or more Internet applications that the individuals started using were Twitter, Google, Facebook, YouTube and Flickr. Besides learning new technologies, some individuals even felt that they would want to start their own personal blog. Many of them also learnt to blog using their mobile phones, which was not taught to them. It evolved from their interaction and challenges with accessibility to the Internet. YouTube came across as quite an exciting prospect for many of them who wanted to create videos with their stories and testimonies and upload them to YouTube for people to see. They felt that it would be a more interactive experience and those watching the video clips would get a better understanding of what they were trying to portray or the message they wanted to deliver.

\section{Discussion}

The main social fulfilment of using Facebook was the need to keep in contact with new and old friends and fellow employees. The interviewees shared and disseminated messages of hope among themselves and others connected to them by using Facebook. This proved not only useful but also important to individuals facing difficult social moments.

Following the fact that the interviewees themselves had been involved in gang-related activities and drugs, the information they had and the experiences and knowledge they share were rich enough to bring impact and encouragement to individuals still battling with the tides of gangsterism and drugs. According to Maslow's hierarchy of needs, social needs are among the essential human needs that should be satisfied in order to avoid a low-self esteem (Maslow 1943). During this research, it was found that the motivation for people to join gangs and be involved in using drugs is a desire to fulfil their missing needs for social interaction and esteem. Facebook has justified the capability of being a medium for encouraging messages and testimonies. The interviewees hoped to expand and continue to use Facebook to encourage one another and others in order to bring about, what they call, a 'social revolution' within their communities.

The results generated from the case study illustrate some form of 'growth' for the individuals. Growth in this context is how these individuals have developed their capabilities and knowledge of Web 2.0 technologies and computer literacy. As stated earlier, some of the individuals had not even switched on a computer before, yet, in the 12 weeks of this study, they learnt how to navigate through the various computer programs and established a structure before posting information on the blog by typing it up in Microsoft Word and using the spell check utility to correct any mistakes.

This may be seen as something easily accomplished by people exposed to computers in their everyday lives but for these individuals, who in some cases dropped out of school at an early age, using the computer was a scary undertaking. Their motivation to write about their stories and experiences must be seen as a significant achievement for them as this entailed leaving their comfort zones.

Access to reliable facilities for them to blog was a problem, as they were limited by the number and availability of computers. In addition, they had to contend with the issue of bandwidth as it restricted them in fully engaging with the technology. Even so, by persisting, they achieved what they desired and overcame limitations such as these and even learnt to blog using their mobile phones. This can be seen as another aspect of growth as it is something they taught themselves about ICT.

The blogging technology could be seen as something new and exciting for the individuals since they actually persuaded others, not in the case study group, to join and see what they were doing. It worked like a chain reaction as one person brought in another person; the barrier to take-up was so low that others could quickly learn to use the technology. The blogging activity also encouraged some of them to return to education and complete their secondary education.

Blogs are still a very new technology to some, yet the procedures to make use of it are simple, hence it should not be seen as an intimidating component of technology. The fact that it can be a provider for various types of information demonstrates that blogs are versatile in the sense that bloggers who put up posts are not restricted to any particular topic. Blogs for this community provided a means of sharing community information. The current site for IDM allows people from the community to blog events as they are happening. 
From the findings, it can be deduced that the blog was used as a catharsis. As mentioned earlier in the literature review, this form of blogging was where an individual used the blog to express feelings and thoughts - usually personal content. In this sense, the stories and feelings posted on a blog were personal to each of the individuals and they must be commended for doing so as it could not have been easy to express themselves using typed words. The blog was also used to document their lives by providing information on what individuals were doing on a daily basis.

From being able to interact with computer facilities and the Internet, apart from blogging, individuals were able to develop their skills regarding social networking. They discovered Facebook and found out how useful Google can be, which provided them with a new Internet facility to work with while they blogged. This led them to acquiring knowledge of other Internet-based technologies such as YouTube, Flickr and Twitter. Just by interacting with the computer and the various Internet facilities, some form of inspiration and bravery was established, as some of them wanted to start their own blogs, while others wanted to upload videos of their testimonies and stories on YouTube to encourage others who were facing the same obstacles that they had overcame. Some of them had already ventured into uploading their 'video blogs' on YouTube.

top

\section{Conclusions and recommendations}

IDM is successfully using experiences of ex-gang members and ex-drug addicts to support people trying to escape similar situations. Through the use of a mobile platform, they are able to disseminate information to their colleagues and to the wider community. Although the members of the group had no previous experience in the use of this technology or ICT generally, they were able to effectively and quickly learn to use Web 2.0 tools to enhance the transfer of their knowledge within the community.

The positive feedback from the individuals' interviews illustrates that the use of Web 2.0 technologies provided a means by which they could communicate how they felt without having to worry about being judged. This is one aspect that demonstrates the positive impact that blogging had on these individuals.

The well-being of an individual determines his or her actions towards building society. Because of daily fluctuations in the level of well-being, the Impact Team members were using Facebook to keep themselves motivated to maintain a balanced level of well-being necessary to encourage members to continue participating in combating gangsterism and drug abuse. Facebook thus proved to have the communication value necessary to improve social well-being among individuals.

Apart from the social benefits resulting from using this type of technology to offer advice and support to the communities on the Cape Flats, it also had another benefit that may be applicable to industry, commerce and the community as a whole, namely the ease with which this particular group of unskilled people learnt to use ICT and which also encouraged them to learn more. The informal and loosely structured nature of blogs encourages the flow of ideas and exchange of knowledge between the members of a community of practice. People can present their ideas and through the comments posted gain instant feedback (peer review). It is also the way the members of the organisation were able to encourage and motivate each other (even when not co-located) through using this technology, which would also be of use to industry.

At a time when South Africa has a serious skills shortage and need more of its people to learn to use ICT, there are two options: either wait until the current school population grows up, which is very much a 'sit back and do nothing attitude', or empower the vast majority of citizens who have missed out previously, opening their eyes to the power they have through their phones, and thereby giving them access to ICT in the wider sense. Already IDM is taking this further and has started Mom 2.0, which is aimed at the mothers and women of the community, allowing them to blog community information. For the office-based workforce, the traditional methods of training are appropriate (e.g. Intentional Computer Driving Licence). However, it may be worth re-examining the methods of ICT training and knowledge sharing for the rest of the workforce if they are to become skilled quickly.

\section{References}

Al-Fadhli, M.S. 2008. Web $2.0+$ Library = Library 2.0/What is Library 2.0? [Unpublished Report]. 
[Online]. Available WWW: http:/ / eprints.rclis.org/ 12679/ 1/ Web_2.0_\% 26_Library_2.0.pdf (Accessed 19 June 2009).

Buice, D., Heath, J., Simmons, M., Smith, J. and Syeda, M. 2007. Social networking Websites and their impact on business today. [Online]. Available WWW:

http:/ / students.kennesaw.edu/ jheath9/ SocialNetworking.doc (Accessed 20 March 2009).

Davies, R. 2005. Blogs and second language learning. [Online]. Available WWW:

http:/ / homepage.mac.com/ rorydavies/ LI N8016/ Blogs.html_(Accessed 25 April 2009).

Dearstyne, W.B. 2005. BLOGS the new information revolution? The Information Management Journal 39(5): 38-44.

Doring, N. and Gundolf, A. 2006. Your life in snapshots: mobile Weblogs. Knowledge, Technology \& Policy 19(1): 80-90.

Ehrmann, S.C. 1998. Studying teaching, learning and technology: a tool kit from the Flashlight Program. Active Learning 9(December):38-42.

Ellison, N.B., Steinfield, C. and Lampe, C. 2007. The benefits of Facebook 'friends: ' social capital and college students' use of online social network sites. J ournal of Computer-Mediated Communication 12 (4).

Frauenheim, E. 2007. Social revolution. Workforce Management 86(18):1-37.

Goodings, L., Locke, A. and Brown, S.D. 2007. Social networking technology: place and identity in mediated communities. Journal of Community \& Applied Social Psychology 17(6):463-476.

Green, E.W. 2005. The web of social networking. [Online]. Available WWW:

http:/ / web.ebscohost.com/ ehost/ detail? vid=4\&hid=117\&sid=f27 b8238-f14d-4780-8334d0f28421b462\% 40sessionmgr104 (Accessed 20 March 2008).

Holahan, C. 2007. Social networking for the faithful. Business Week Online. [Online]. Available WWW:

http:/ / www.businessweek.com/ technology/ content/ may2007/tc20070521_126201.htm (Accessed 1 May 2009).

Kay, R. 2007. Online social networks. ComputerWorld 41(40):56.

Lorica, B. 2009. Active Facebook users by Country. O'Reily Radar. [Online]. Available WWW: http:/ / radar.oreilly.com/ 2009/ 04/ active-facebook-users-by-country-200904.html (Accessed 30 April 2009).

Maslow, A.H. 1943. A theory of human motivation. Psychological Review 50:370-396.

Mathews, B.S. 2006. Do you Facebook? Networking with students online. C \& RL News 67(5):306307.

Nardi, A.B., Schiano, J.D., Gumbrecht, M. and Swartz, L. 2004. Why we blog. Communications of the ACM 47(12): 41-46.

O'Reilly, T. 2005. What is Web 2.0? O'Reilly Network (September 30). [Online]. Available WWW: http:/ / www.oreillynet.com/ pub/ a/ oreilly/ tim/ news/ 2005/ 09/ 30/ what-is-web-20.html (Accessed 5 May 2009).

Parker, M., Wills, G. and Wills, J. 2008. Community in tension (CiT). Technical Report ECSTR-LSL08002, ECS, University of Southampton.

Peek, R. 2005. Web publishing 2.0. Information Today 22(10): 17-18.

Roth, M.M. 2004. How journalists see the blogosphere. Annenburg School for Communication. University of Pennsylvania: 1-34. [Online]. Available WWW: 
http://java.cs.vt. edu/public/projects/digitalgov/papers/blogs.pdf (Accessed 27 January 2009).

Stanfield, B.A. 2007. Blog time: the popularity of blogs is exploding. Find out how you can reap the benefits (advice: marketing moves). Art Business News (1): 46.

Standing, A. 2003. The social contradictions of organised crime on the Cape Flats. Institute for Security Studies Papers, 2003. [Online]. Available WWW: http:/ / www.iss.co.za/ index.php?

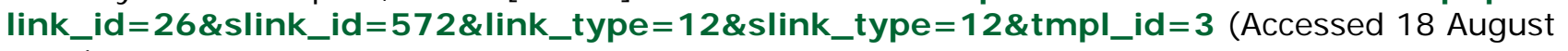
2009).

Vaughan, N. 2006. The use of Wikis and Weblogs to support deep approaches to learning. Teaching and Learning Centre, University of Calgary. Research Review 1(3):47-60.

Welman, C., Kruger, F. and Mitchell, B. 2005. Research methodology. Third edition. Oxford University Press of Southern Africa. 